\title{
PROGRAMA DE DESARROLLO ALTERNATIVO EN COLOMBIA FAMILIAS GUARDABOSQUES. VISIÓN DESDE EL ENFOQUE DEL DESARROLLO TERRITORIAL RURAL
}

\author{
Omar Felipe Giraldo* \\ Ricardo Andrés Lozada** \\ * Médico Veterinario. Universidad Nacional de Colombia. Magister (c) en Desarrollo \\ Rural. Universidad Nacional de Costa Rica. Correo Electrónico: \\ omarfgiraldo@hotmail.com \\ ** Politólogo. Universidad Nacional de Colombia. Especialista en Planeación del \\ Desarrollo Regional. Universidad de los Andes. Correo Electrónico: \\ ricardoandreslozada@yahoo.com.ar
}

Manizales, 2008-11-17 (Rev. 2008-12-09)

\begin{abstract}
RESUMEN
El programa Familias Guardabosques (PFGB) es una iniciativa de desarrollo alternativo que el gobierno colombiano ha ejecutado desde el año 2003 en 121 municipios y que ha beneficiado a 105.494 familias. Su principal objetivo se basa en que comunidades campesinas, indígenas y afrodescendientes abandonen voluntariamente sus cultivos ilícitos o se comprometan a nunca insertarse en esta actividad. En este artículo, se analiza el PFGB a partir de los elementos conceptuales del enfoque del Desarrollo Territorial Rural (DTR). Las reflexiones se enfocan en la necesidad de implementar un criterio territorial en las políticas de desarrollo alternativo, en donde se distinga la pluriactividad de la economía rural, una mayor integración rural - urbana, aumento de la participación, creación de una red interinstitucional entre el nivel local y nacional, y la consolidación de mancomunidades.
\end{abstract}

\section{PALABRAS CLAVE}

Desarrollo alternativo, cultivos ilícitos, desarrollo territorial rural.

\section{ALTERNATIVE DEVELOPMENT PROGRAM IN COLOMBIA, FOREST-GUARD FAMILIES. VIEW FROM THE APPROACH OF TERRITORIAL RURAL DEVELOPMENT.}

\begin{abstract}
The Forest-Guard Families program (PFGB) is an initiative of alternative development that the Colombian government has implemented since 2003 in 121 municipalities, benefiting 105,494 families. Its main objective is for farmer, indigenous and afro-Colombian communities to voluntarily abandon the cultivation of illicit crops or to commit to never practicing this activity again. This article reviews the PFGB from the conceptual elements of the Territorial Rural Development (DTR)
\end{abstract}


approach. The reflections are focused on the need to implement a territorial approach in alternative development policies, distinguishing the multiple activities of rural economy, a greater rural-urban integration, increased participation, the creation of an interagency network between local and national levels, and the consolidation of municipal associations.

\section{KEY WORDS}

Alternative development, illicit crops, territorial rural development

\section{INTRODUCCIÓN}

La discusión sobre la lucha contra cultivos ilícitos tuvo su inicio en la Convención de las Naciones Unidas Contra las Drogas realizada en 1961. En dicha reunión, la propuesta planteaba la erradicación de los arbustos de coca y amapola, y se establecía un período de 25 años para la eliminación de todos los cultivos ilícitos. La anterior concepción no reflexionaba acerca de las causas sociales, políticas, económicas y culturales de este fenómeno, ni diferenciaba las estrategias de intervención para grandes y pequeños productores. Casi treinta años después, en el año de 1988, se celebró la Convención de las Naciones Unidas contra el Tráfico llícito de Estupefacientes y Sustancias Psicotrópicas, en donde se comenzó a generar un cambio en la dirección de la problemática. Sin embargo, es en 1998, durante la sesión especial de la Asamblea General de Naciones Unidas sobre el problema mundial de las drogas, UNGASS, cuando se consolidó el concepto de desarrollo alternativo como instrumento para avanzar en la reducción y sustitución de cultivos ilícitos (Cortés, 2007: 264 -265). En esta sesión, el desarrollo alternativo fue definido como:

“(...) un proceso destinado a impedir y eliminar el cultivo ilícito de plantas que contengan estupefacientes y sustancias psicotrópicas mediante la adopción de medidas de desarrollo rural expresamente concebidas con tal fin, y que se lleva a cabo en el contexto de un crecimiento económico nacional sostenido y de los esfuerzos por alcanzar un desarrollo sostenible de países que están tomando medidas contra las drogas, teniendo presentes las características socioculturales especiales de las comunidades y grupos destinatarios, y en el marco de una solución permanente y global de la problemática de las drogas ilícitas" (UNGASS, 1998).

El desarrollo alternativo, en otras palabras, es una estrategia complementaria a la interdicción, el cual usa el desarrollo rural con el propósito de que familias campesinas vinculadas a los cultivos ilícitos (o que estén en riesgo de serlo), se inserten en una cultura de la legalidad, a través de alternativas lícitas que contemplen la multiplicidad de variables que perpetúan el fenómeno.

En Colombia, la problemática de los cultivos ilícitos comienza a finales de la década del setenta, cuando diversos factores, como el aumento del consumo de drogas en Estados Unidos y Europa, el contrabando, y las condiciones geopolíticas propicias de la nación, entre muchas otras causas, se apiñaron y estructuraron la base de lo que más adelante sería una economía ilegal compleja y expansiva, que impactaría todos los componentes del sistema social colombiano. 
En la actualidad, y de acuerdo a datos del proyecto de Sistema Integrado de Monitoreo de Cultivos ilícitos (SIMCI), el país se constituye en el mayor productor de coca en todo el mundo con 99.000 hectáreas sembradas y responsable de la producción del $60 \%$ de la cocaína del planeta.

Los Gobiernos, para hacer frente a esta situación, han implementado estrategias combinadas, con las cuales se ha logrado disminuir en $60 \%$ las hectáreas sembradas con coca entre el 2000 y 2007. Por un lado, se han efectuado actividades de interdicción, las cuales hacen referencia a las acciones que el Estado coordina y ejecuta mediante el uso de la fuerza, con el objetivo de atacar la producción, procesamiento y tráfico de drogas. En particular, para el combate contra la producción de coca y amapola, las principales acciones han estado centradas en la fumigación área con glifosato y la erradicación manual forzada.

Por otro lado, y como complemento a la interdicción, se ha implementado la estrategia del desarrollo alternativo, la cual tiene sus antecedentes en el año de 1986, cuando las Naciones Unidas ejecutaron pequeños proyectos en los departamentos de Cauca, Putumayo, Guaviare, Caquetá y Nariño (García, 2000: 153). Esta iniciativa, fue apoyada por el gobierno de Virgilio Barco (1986-1990) el cual, a través del Plan Nacional de Rehabilitación, puso en marcha algunas obras de infraestructura y dio impulso a la sustitución de cultivos ilícitos con un enfoque a corto plazo y un fuerte sesgo económico (Ortiz, 2000: 175).

No obstante, fue a partir del Gobierno de Ernesto Samper (1994-1998) que el Estado diseñó e implementó un programa de desarrollo alternativo denominado Plan Nacional de Desarrollo Alternativo (PLANTE), el cual dio continuidad el Gobierno de Andrés Pastrana (1998-2002). En él, se trazó la necesidad de "emprender acciones para la generación de opciones productivas lícitas, rentables y ambientalmente viables, para campesinos e indígenas, en orden a superar las condiciones que facilitaron el establecimiento de cultivos ilícitos" (Decreto 0472 de 1996).

Este programa se enfrentó con serios problemas, como la falta de mercados para la comercialización de productos, el control territorial de grupos armados, problemas de concertación con las comunidades debido a grandes flujos de ingreso como resultado de esta actividad, descomposición social, y debilitamiento institucional. Pero, probablemente, el problema más grande fue la limitada disponibilidad de recursos, con el consecuente estancamiento de procesos. Adicionalmente, tuvo un permanente desfase entre planeación, ejecución y vigencias presupuestales (Ortiz, 2000: 175-178).

Pese a los esfuerzos en complementar las estrategias policivas y militares con desarrollo alternativo, en el año 2000 se contabilizó la mayor cantidad de cultivos ilícitos registrada en la historia colombiana con 163.000 hectáreas de coca. Este aumento, coincidió con la peor crisis del sector agropecuario de la década anterior, lo cual hizo que la participación del sector en la economía nacional cayera entre 1991 y 2005 del 16,3\% al 13,4\%, y desde el año de 1995 hasta el año 2002, se dejaran de sembrar 700 mil hectáreas de cultivos transitorios (Robledo, 2007: 61).

SIMCl estima que existen 80.000 hogares vinculados a los cultivos ilícitos con un promedio de área sembrada de 0,82 hectáreas. Pese a los ingentes esfuerzos en interdicción (66.805 de hectáreas erradicadas y aspersión aérea de 153.135 hectáreas en sólo el año 2007), los cultivos siguen aumentando al pasar de 78.000 hectáreas en 2006 a 99.000 en 2007 (UNODC/SIMCI, 2008: 6-7). Este aumento 
indica que es necesario aumentar los esfuerzos para evitar la resiembra de cultivos ilícitos, ofreciendo alternativas ambientales, sociales y culturales económicamente sostenibles, a las comunidades rurales víctimas de este flagelo.

En este artículo nos proponemos analizar una de las estrategias del desarrollo alternativo que ejecuta el Gobierno colombiano en la actualidad, denominada Programa Familias Guardabosques (PFGB) a partir del enfoque del Desarrollo Territorial Rural (DTR). Inicialmente, expondremos algunas generalidades de la perspectiva teórica, así como las características del programa. Posteriormente, entraremos a estudiar los componentes del instrumento político a la luz del DTR. Y finalmente presentaremos algunas reflexiones en torno a este debate.

\section{DESARROLLO TERRITORIAL RURAL (DTR) Y PROGRAMA FAMILIAS GUARDABOSQUES (PFGB)}

Como se ha visto, el desarrollo alternativo es una estrategia que utiliza el desarrollo rural como mecanismo para que poblaciones involucradas con los cultivos ilícitos se inserten en una cultura de la legalidad. Dentro de tal criterio, es pertinente que las políticas públicas orientadas hacia este fin, incorporen en su diseño y ejecución los nuevos paradigmas del desarrollo rural.

En particular, un enfoque teórico que ha tenido una notable aceptación entre la comunidad académica, agencias multilaterales de financiamiento y organizaciones internacionales de cooperación, es el denominado desarrollo territorial rural (DTR), el cual, de acuerdo con Alexander Schejtman y Julio Berdegué (2004), se define como: "un proceso de transformación productiva e institucional en un espacio rural determinado, cuyo fin es reducir la pobreza rural" (Shetjman y Berdegué, 2004: 30).

La concepción del DTR se diferencia de los enfoques tradicionales del desarrollo rural en que en esta perspectiva se asume el territorio como el nuevo objeto de atención, en contraste con las antiguas visiones sectoriales. En este sentido, el DTR rompe el sesgo agrícola que han tenido las políticas públicas en el pasado y distingue la diversidad de sectores económicos que convergen en los espacios rurales, ya sean actividades basadas en los recursos naturales (como agricultura, ganadería, pesca, minería, ecoturismo, servicios ambientales) o bien actividades de transformación agroindustrial, servicios, construcción y comercio local (Echeverri, 2005: 24-26).

En el DTR el concepto de territorio sobrepasa lo eminentemente espacial y, en contraposición, se define como un producto social e histórico, dotado de recursos naturales, formas de producción, comercialización, redes institucionales y formas de organización particulares (Sepúlveda et al, 2003: 69). Es, a su vez, el escenario donde los valores sociales forman consenso, marcan identidad y generan solidaridad (Linck, 2006). Asimismo, en esta perspectiva se conjugan elementos de simultaneidad, enfoque de abajo hacia arriba del desarrollo, descentralización, competitividad de la economía rural y articulación de las instituciones públicas y la empresa privada (Sumpsi, 2006: 4).

Pese a estos loables elementos teóricos, en el contexto del desarrollo alternativo, la perspectiva del DTR no ha sido hasta ahora abordada para adecuarla a sus propias particularidades, motivo que nos ha incentivado a utilizar el enfoque del DTR para analizar el PFGB. 
Este es un programa gubernamental de la Agencia Presidencial para la Acción Social y la Cooperación Internacional (Acción Social) que comenzó en Colombia en el año 2003 con el objeto de involucrar a comunidades campesinas, indígenas y afro-descendientes, víctimas de los cultivos ilícitos o que estén en riesgo de serlo, en la protección de ecosistemas en los que habitan, así como en la inclusión de una cultura de la legalidad. La estrategia del PFGB, ha sido la entrega de un subsidio condicionado de $\$ 300$ USD en pagos bimestrales durante 36 meses a las familias beneficiarias (posteriormente se disminuyó el incentivo a \$204 USD y el tiempo a 18 meses), con el compromiso de que dichos hogares erradiquen voluntariamente sus cultivos ilícitos.

Las áreas se focalizan de acuerdo con criterios ambientales, aunque en la práctica se hace a partir de la voluntad de las familias que quieran ingresar al programa. Una vez se seleccionan las áreas de intervención, se firman contratos individuales y colectivos por vereda. En un comienzo el PFGB permitía que sólo las familias beneficiarias estuvieran libres de coca o amapola en los predios inscritos, lo que generaba falta de compromiso, e incumplimiento. Esta lección aprendida hizo que se cambiara el condicionamiento por la erradicación voluntaria de toda la vereda para la entrada y permanencia en el programa. Lo anterior significa que si una sola familia incumple el convenio hecho con el gobierno, todas las demás familias de esa misma vereda son retiradas del programa.

EI PFGB tiene dos componentes. El primero, denominado Técnico-Ambiental, busca realizar actividades de conservación, recuperación y preservación de los bosques. Asimismo, tiene por objeto apoyar la creación de proyectos productivos sostenibles en las líneas de café, cacao, caucho, palma africana, cultivos forestales maderables, caña panelera, piscicultura, apicultura, sistemas silvopastoriles, ecoturismo y artesanías. Un segundo componente ha sido designado Social, el cual se propone promover la unidad familiar, mejorar relaciones entre vecinos, la formación y/o fortalecimiento de organizaciones comunitarias, estimular el ahorro y el liderazgo. Estas actividades se ejecutan con entidades que realizan un acompañamiento específico a las familias beneficiarias.

El programa se ha trazado como objetivos los siguientes: incentivar la cultura de la legalidad, el desarrollo económico de las familias, la generación de capital social, la presencia institucional y la protección de ecosistemas ambientalmente estratégicos.

Un segundo programa gubernamental de desarrollo alternativo se denomina Proyectos Productivos (PPP), el cual busca establecer o fortalecer proyectos sostenibles para la sustitución sostenible de cultivos ilícitos. El gobierno nacional ha integrado estos programas con el objeto de que las organizaciones productivas de base conformadas con el PFGB hagan un tránsito hacia el PPP.

Hasta el momento, el PFGB ha beneficiado a 105.494 familias en 121 municipios a lo largo y ancho de toda la geografía colombiana. De acuerdo con cifras de la Oficina de las Naciones Unidas contra la Droga y el Delito (UNODC), la cual realiza en convenio con el Gobierno para el seguimiento y evaluación del programa, entre el año 2004 y 2007, se había logrado eliminar voluntariamente 9.036 hectáreas (6.473 de coca y 2.562 de amapola), y se mantiene la protección de 282.588 hectáreas de bosque (UNODC, 2007).

Si bien el PFGB no es un programa que haga uso del enfoque del DTR, consideramos pertinente usar las unidades de análisis de la teoría, con el propósito 
de encontrar elementos que puedan aportar al mejoramiento del diseño y ejecución de las políticas públicas de desarrollo alternativo en Colombia.

\section{METODOLOGÍA}

Para el desarrollo de este análisis, se seleccionaron criterios de las propuestas hechas por el Instituto Interamericano de Cooperación para la Agricultura (IICA), y de académicos como Alexander Schejtman y Julio Berdegué, Alain de Janvry y Elisabeth Sadoulet. Una vez escogidas las variables, se procedió a cruzar la información de terreno a partir de datos etnográficos de entrevistas y observaciones recopiladas en notas de campo por los autores del presente artículo. En total, se visitaron 46 municipios ${ }^{1}$ durante las diferentes fases del programa entre febrero de 2008 y agosto de 2009.

Para este trabajo seleccionamos variables de los tres niveles de transformación propuestos por Shetjman y Berdegué. Para la primera, denominada productiva, se escogieron criterios como el rescate de la economía local, la economía territorial, la demanda externa al territorio, la competitividad territorial y la gestión ambiental. Para una segunda, llamada institucional, se distinguieron conceptos como la presencia institucional, la participación y descentralización del gobierno, y la coordinación de las políticas públicas. Y por último, en la tercera variable señalada como social, se escogieron elementos como la generación de capital social, enfoque de género, diversidad cultural, y desarrollo de capacidades.

De acuerdo con esta selección de la literatura disponible sobre DTR, intentaremos reflexionar sobre cada uno de estos apartados de la teoría y su aplicabilidad en el PFGB.

\section{Visión del PFGB desde el enfoque del DTR}

\section{Transformación productiva}

En un primer lugar, nos concentraremos en el rescate de la economía local, concepto acuñado por la teoría del DTR para referirse a la necesidad de incentivar esta economía en los territorios. Este es un reconocimiento a las transacciones que mayoritariamente se efectúan en los espacios rurales. En consecuencia, la teoría plantea que las estrategias de crecimiento y desarrollo rural deberían vincular de manera explícita a estos mercados. Tal afirmación rompe las preocupaciones excesivas acerca de los mercados internacionales y posicionan, de nuevo, el consumo interno como motor económico de las naciones (Sepúlveda et al, 2003: 79).

Específicamente refiriéndonos al PFGB, el programa en un comienzo no contemplaba el establecimiento de proyectos productivos de ninguna índole. Por tal razón, en las primeras fases del programa el subsidio económico condicionado no contaba como requisito el ahorro de parte del mismo. Aparte de esta situación, existió falta de claridad por parte de los formuladores de la estrategia, sobre los objetivos perseguidos, inicialmente limitados a la erradicación voluntaria y a emprender acciones para favorecer la revegetalización natural y la reforestación de áreas degradadas.

Por lo anterior, durante las primeras fases del programa, los logros relativos a la activación de una transformación productiva en áreas dominadas por el narcotráfico fueron mínimas, y se limitaron a las actividades que los propios beneficiarios 
emprendieron en sus predios para retornar a la agricultura de subsistencia de las economías campesinas, y el retorno a cultivos de pan coger abandonados por la siembra de coca y amapola. En efecto, este último aspecto fue un fenómeno positivo no esperado que muchos campesinos emprendieron con el dinero del subsidio.

En estos estados iniciales de la estrategia, los proyectos productivos comenzaban al final del programa. Tal situación generó que una vez culminado el incentivo condicionado, las familias guardabosques no tuvieran aún una alternativa económica diferente a los cultivos ilícitos. Según UNODC, tan sólo el $36 \%$ de estas familias se encuentran vinculadas a proyectos productivos de las primeras tres fases del programa (UNODC, 2007: 11). Efectivamente, un beneficiario indígena del alto Putumayo al culminar el programa en su municipio manifestó que: "con el fin del PFGB queda la incertidumbre de que tal vez se vuelva a esta actividad (cultivos ilícitos) ya que no hay otros medios de sostenimiento (...). Algunos consideran la opción de irse de raspachines"

Por otro lado, muchos proyectos aún se ven limitados por la falta de infraestructura vial para sacar los productos de sus predios. A diferencia del mercadeo de la base de coca, la cual no necesita de grandes equipamientos, pues la producción de una hectárea de coca puede transportarse con facilidad en un morral, los productos lícitos demandan carreteras para poder llegar a los mercados. Es de resaltar que la mayoría de los territorios en donde ha operado el programa son áreas rurales marginales sin dotación adecuada de infraestructura. Esta es una de las razones por la cuales Shetjman y Berdegué afirman que: "La transformación productiva y el desarrollo institucional se deben abordar de forma simultánea en los programas de DTR" (Shetjman y Berdegué, 2004: 5). Ambos elementos se condicionan mutuamente y son necesarios para lograr reducciones significativas y sustentables de la pobreza rural. Efectivamente, no es posible hacer una transformación productiva ni desarrollo alternativo, sin dotación de carreteras y presencia institucional.

En un segundo lugar, se utilizará el análisis de la economía territorial, que, cómo se explicó anteriormente, reconoce la multiplicidad de sectores económicos de los espacios rurales. En este sentido, el PFGB ha apoyado el ecoturismo, artesanías y tiendas comunitarias rurales. Sin embargo, el programa generalmente ha mantenido un sesgo agrícola, lo cual se puede ejemplificar con el criterio que actualmente tiene el programa de retirar a las personas que no devenguen su sustento exclusivamente del predio inscrito, juicio que desconoce la pluriactividad de las economías campesinas contemporáneas.

En esta misma línea, es necesaria la articulación de la ruralidad con los núcleos urbanos, a partir de la conformación de redes y encadenamientos productivos. El PFGB no ha hecho esfuerzos suficientes en esta materia, salvo en la promoción de algunos mercados campesinos que, si bien son exitosos como eventos, no han tenido mayor acogida para su posterior continuidad.

Un elemento supremamente exitoso dentro del PFGB ha sido la compra de tierras. De acuerdo con UNODC entre 2004 y 2007, 11.405 familias guardabosques habían comprado 43.378 hectáreas, con parte de los $\$ 18$ millones de dólares ahorrados. Esta dinamización del mercado de tierras condujo a un aumento del precio por hectárea y a la valorización de los predios rurales. 
La falta de acceso a la tierra es un limitante para el establecimiento de proyectos productivos. Sin embargo, y según nuestro criterio, no es suficiente la vía del mercado de tierras para el desarrollo alternativo y es necesaria una reforma agraria integral para ayudar a generar una economía territorial equitativa, disminuir la pobreza rural, y frenar el avance de las economías del narcotráfico, las cuales ayudan a perpetuar el conflicto armado en Colombia.

Entre los fenómenos evidentes en la transición de la ilegalidad a la legalidad con el PFGB, se encuentran la recesión económica de los territorios como resultado del rompimiento de las economías de narcóticos, la pérdida de interés en el trabajo en jornales agropecuarios por su baja remuneración, y la migración rural-urbana o rural-rural de los raspadores de hoja de coca.

En contraste, los territorios que no habían experimentado con cultivos ilícitos, el fenómeno fue distinto, pues se percibió un aumento del comercio local, transporte, y construcción por el mejoramiento de viviendas de las familias. Sin embargo, una vez terminado el programa, se confirmó que esta era una economía ficticia que se había creado en los municipios a partir del subsidio del PFGB.

Si bien el PFGB mejoró la calidad de vida de muchas familias que construyeron o arreglaron viviendas, ayudó a reactivar la agricultura campesina y a generar proyectos lícitos e incentivó la compra de tierras, ha faltado una perspectiva económica sostenible de integración urbana-rural que ayude a configurar una economía territorial.

La tercera variable escogida es la demanda externa al territorio, criterio reconocido por el DTR para ilustrar la importancia del aprovechamiento de las oportunidades de la globalización. En este sentido, el PFGB, una vez aprendió la lección que le dejó la falta de objetivos relativos a la transformación productiva durante las primeras fases, se ha esmerado por incluir a sus beneficiarios dentro de cadenas productivas de agro-exportación como el cacao, el café, el caucho, la palma de aceite, los cuales son una verdadera alternativa para campesinos de los territorios donde opera el programa. La inclusión de pequeños productores a cadenas dominadas por grandes empresas, demuestra que es factible democratizar las oportunidades de la liberación económica, mediante la reconversión productiva de los territorios.

Un cuarto elemento de análisis es la competitividad territorial, la cual consiste en el salto que deben asumir los territorios para transformar una competitividad privada, basada únicamente en la competencia de firmas individuales, en una competitividad territorial a partir de la innovación tecnológica y la generación de redes de organizaciones, "clusters" y cadenas productivas (Sepúlveda et al, 2003). En este aspecto, es importante resaltar cómo el programa ha tenido como objetivo reciente, generar aglomeraciones de empresas con el propósito de crear una competitividad territorial. Efectivamente, se han creado marcas guardabosques como el "Café Doña Juana" de la organización AAA de Albán Nariño o "Mieles de la sierra" en Santa Marta, entre muchas otras. Aún los mercados de estos productos son incipientes y se constituyen como un verdadero reto en el que debe participar activamente la empresa privada.

En el aspecto de la gestión del conocimiento ha sido importante la estrategia de "intercambios", en los cuales familias guardabosques visitan experiencias para conocer algunas experiencias de otros campesinos guardabosques exitosos, propiciando un diálogo de saberes entre pares. 
Una última variable de suma importancia para la configuración del desarrollo de los territorios rurales, es la visión de sustentabilidad ambiental. El PFGB, de acuerdo con su propio nombre, ha hecho de este objetivo el sustento de su existencia. Ante la Asamblea General de las Naciones Unidas, el Presidente de Colombia ha presentado este programa como una de las iniciativas mundiales más grandes contra el calentamiento global.

Los logros en este aspecto han sido notables. En primer lugar la sensibilización propiciada por el programa en relación con la necesidad de cuidar los recursos naturales ha hecho que muchos campesinos hayan abandonado prácticas de quema para la siembra e implementen buenas prácticas agrícolas, así como que hagan campañas de reforestación con especies nativas y mantenimiento de fuentes hídricas. SIMCI afirma que se han recuperado en las áreas donde opera el programa 53.477 hectáreas de bosque y rastrojo alto (UNODC/SIMCI, 2008: 60). Por otro lado, el manejo de basuras mejoró con las capacitaciones de los acompañamientos. Existieron logros en temas de saneamiento básico, como en la construcción de unidades sanitarias o uso de letrinas, así como en la construcción de acueductos veredales con dineros del incentivo.

No obstante, se han presentado dificultades por parte de familias que no ingresan al PFGB, las cuales continúan haciendo las prácticas habituales. También el monocultivo es criticado por muchos beneficiarios. A este respecto, un líder del Magdalena Medio manifestó que: "La palmicultura genera problemas ambientales, porque se talan los bosques, a veces hasta el área de protección de fuentes hídricas. Este tipo de cultivo desincentiva la siembra de pan coger, poniendo en riesgo la seguridad alimentaria".

Una carencia percibida dentro de la estrategia de guardabosques es la ausencia de pagos por servicios ambientales (PSA). Esta es una de las oportunidades que podrían desarrollarse en el país, emulando a otras naciones como Costa Rica, para generar otras alternativas económicas a familias que habitan dentro de ecosistemas estratégicos.

\section{Transformación institucional}

Este es un segundo nivel de transformación de los territorios rurales en el cual se ha escogido la presencia institucional como primer criterio de reflexión del contexto teórico utilizado para el análisis. La importancia de esta variable dentro del concepto del desarrollo alternativo, radica en que en los territorios víctimas de cultivos ilícitos se ha presentado una ausencia dramática de la institucionalidad. En Colombia, la presencia en estos espacios de grupos armados y bandas al servicio del narcotráfico ha socavado la gobernabilidad y la confianza estatal. En este aspecto, el PFGB ha tenido logros evidentes, no sólo por la pacificación de las áreas sino por la llegada de instituciones públicas y privadas que nunca antes habían hecho presencia local.

La presencia de un conglomerado de instituciones permitió la dotación de infraestructura local. De acuerdo con algunos líderes comunitarios, gracias al PFGB hubo mejoramiento de alcantarillado, se crearon salones comunales, restaurantes escolares, polideportivos, comedores para ancianos, baterías sanitarias para las escuelas, mejoramiento de vías y salas de cómputo.

La participación y descentralización es un segundo elemento escogido para la reflexión. En tal aspecto, existen elementos positivos y negativos contrastantes en 
este instrumento político. Efectivamente, el PFGB involucró un elemento innovador supremamente exitoso para la acción colectiva, denominado Comités Comunitarios de Verificación y Control Social (CCVCS), los cuales son organizaciones de cinco beneficiarios encargados de representar a cada vereda en todos los asuntos relacionados con el programa. El PFGB también se ha encargado de fortalecer las Juntas de Acción Comunal (JAC) de cada una de las veredas para fortalecer la institucionalidad local, el trabajo asociativo, el empoderamiento y la gestión local. Asimismo, se ha preocupado por ayudar a crear organizaciones productivas de base que hagan un tránsito hacia el programa gubernamental de desarrollo alternativo PPP.

Pese a estos notables avances de presencia institucional y creación y/o fortalecimiento de organizaciones sociales, el programa ha tenido serios vicios de verticalidad en el diseño de su política. En efecto, la comunidad coincide en la falta de participación comunitaria y la imposición de los proyectos productivos por parte del Gobierno. Otros actores locales, como los acompañamientos, manifiestan que si bien existió concertación con la comunidad en su elaboración, el Gobierno Nacional no los tuvo en cuenta en el momento de hacer el diseño y ejecución de tales proyectos.

También es de anotar cómo el papel de las alcaldías municipales y las gobernaciones no ha sido protagónico en el PFGB. Hay una ausencia de articulación de redes con los actores locales presentes en el territorio. La centralización del poder en manos del Ejecutivo ha sido un evidente retroceso en este proceso.

La propuesta del DTR plantea como indispensable el diseño de políticas públicas de abajo hacia arriba. Sergio Boiser de la CEPAL ha expresado que debe existir un proyecto político regional definido como "...una proposición con un alto nivel de participación social", sin el cual es imposible el desarrollo endógeno (Boisier, 1999: 93). El programa Leader de la Unión Europa ha sido ejemplo de esta perspectiva participativa a nivel local, con importantes resultados en las áreas rurales de ese continente.

Un tercer elemento planteado por el enfoque del DTR, es la necesidad de que exista una coincidencia de las políticas macro, sectoriales y locales. El PFGB, al ser un programa presidencial, ha sido coherente con las políticas nacionales implementadas a partir del año 2002. No obstante, como se ha expuesto anteriormente, se ha relegado a los gobiernos locales y regionales. Asimismo, es llamativa la ausencia del Ministerio de Agricultura y la coordinación con sus políticas públicas dentro de la estrategia del desarrollo alternativo en Colombia.

También se han presentado contradicciones en las diferentes estrategias de combate contra los cultivos ilícitos. En ocasiones, se han fumigado extensos territorios de familias que habían comenzado su transición hacia la legalidad, con proyectos productivos, lo cual es una evidente incongruencia con los objetivos del desarrollo alternativo.

\section{Transformación social}

EI DTR reconoce la cohesión social como un criterio fundamental para reducir la pobreza rural. De acuerdo con Jorge Mora y Jorge María Sumpsi (2004) el capital social de las áreas rurales está conformado por "... los lazos de parentesco y vecindad; las relaciones de reciprocidad; las normas compartidas; las relaciones 
interpersonales; las asociaciones y las acciones colectivas..." (Mora y Sumpsi 2004: 33). En tal concepción, el PFGB ha tenido logros cualitativos significativos que es pertinente resaltar dentro de la presente discusión.

Las comunidades suelen manifestar que el programa ha propiciado una visión compartida de futuro entre los miembros de las comunidades, ha mejorado la organización comunitaria reflejada en el incremento de los trabajos comunitarios para el mantenimiento de la infraestructura o la integración por medio de campeonatos interveredales de fútbol y bazares. Con respecto lo anterior, un líder del CCVCS en el departamento de Nariño manifestó que: "había antes una desunión; con el PFGB fue volver la comunidad una familia"

Asimismo, se ha fortalecido el tejido humano al crear solidaridad manifiesta en las ayudas prestadas a los campesinos no beneficiarios del programa. Los lazos de confianza se han demostrado en la distribución de responsabilidades entre beneficiarios, como la asignación de tesoreros y representantes, y en la unión forjada por la integración con los vecinos de la misma vereda. El programa también ha permitido la creación de nuevos liderazgos por medio de los CCVCS.

En las comunidades indígenas se ha propendido por ajustar los objetivos del programa con sus "planes de vida", los cuales son documentos de desarrollo indígena hechos por las mismas comunidades, reconociendo su cultura y teniendo como propósito recobrar las tradiciones como su lenguaje, el trueque o el cambalache.

Otra característica importante que plantea del DTR para emprender la senda de un desarrollo rural exitoso y sostenible, es la incorporación de la perspectiva de género, para romper la opresión y marginación que nuestras campesinas e indígenas han sufrido por siglos de dominación patriarcal. A este respecto, el PFGB ha diseñado su estrategia para que las mujeres sean las titulares del incentivo. Esta substancial lección ha ayudado a que un número importante de mujeres se encuentren liderando proyectos productivos y se hayan encontrado nuevas lideresas.

Con respecto al desarrollo de las potencialidades humanas, el PFGB ha hecho algunos avances en el tema de la capacitación. Teóricos como Amartya Sen postulan que se debe permitir el desarrollo de las capacidades de las comunidades, como principal medio para la superación de la pobreza. En este sentido, los acompañamientos e instituciones estatales como el Centro Nacional de Aprendizaje (SENA) o Dansocial, han hecho labores importantes para incentivar el uso de nuevos conocimientos en técnicas agropecuarias, iniciativas empresariales, organización y economía solidaria.

No obstante, el PFGB también ha generado algunos impactos negativos en las comunidades, tanto el paternalismo propiciado por la subvención otorgada así como el mal manejo que muchos beneficiarios le han dado al dinero. De la misma manera, el acostumbramiento al dinero regalado y la pereza para emprender acciones productivas, han sido otras externalidades negativas. En parte, estas situaciones han sido motivadas por demoras burocráticas en las contrataciones de las entidades que hacen los acompañamientos y la consecuente ausencia de asesoramiento para cumplir con los objetivos del subsidio condicionado.

Por otro lado, se dividieron muchas comunidades entre beneficiarios y quienes no ingresaron al programa. Al respecto un guardabosque entrevistado dijo que: "algunos vecinos que no estaban en el PFGB trataron de sabotear el programa con 
hostilidad y chismes y quienes tenian poder de mando trataban de poner trabas a cualquier iniciativa". También, en algunos casos, los líderes han sido amenazados por productores de coca, acusados de delatores o por los grupos armados ilegales que se sustentan mediante las actividades del narcotráfico.

Como se ve, las políticas públicas con asignaciones presupuestales importantes y con estrategias de subvención económica, tienen diversos impactos sociales, tanto positivos, como negativos, en las comunidades en donde se hace la intervención pública. No obstante, en suma, este programa ha tenido elementos interesantes en términos de conformación de redes, cohesión social y generación de tejido humano. Probablemente, la transformación social es el mayor logro de esta iniciativa, de enorme importancia para la creación de una cultura de la legalidad y la erradicación sostenible de los cultivos ilícitos. Por su parte, es necesario aprender de los impactos negativos para atenuarlos en futuros programas de desarrollo alternativo que utilicen estrategias similares.

A continuación, y a modo de conclusión, se presentarán algunas reflexiones sobre el programa anteriormente analizado a la luz de la teoría del DTR.

\section{REFLEXIONES FINALES}

Antes de abordar los elementos finales de la reflexión de este debate, es preciso mencionar las bondades que tiene el ejercicio de sistematizar políticas públicas, con base en elementos teóricos como el presentado en el presente artículo. Los intentos de retroalimentar a los tomadores de decisiones con los aportes de la academia, así como a las autores que construyen teoría, con las experiencias en terreno, constituye la articulación ideal para emprender las acciones de desarrollo que necesitan nuestras naciones. En particular, los elementos conceptuales de la perspectiva del Desarrollo Territorial Rural, en nuestra opinión, representan aportes sustantivos para enriquecer la política de desarrollo alternativo en Colombia.

En primer lugar, la necesidad de tomar al territorio como unidad de intervención, contando con todos sus actores y actividades económicas, es un reto que deben emprender los programas gubernamentales, dentro de los cuales se insertan las políticas de desarrollo alternativo en el país. La experiencia enseña que proyectos con pequeña población suelen generar islas de desarrollo, si se abordan de una manera estratégica e integral para todo un territorio en concreto. La articulación rural-urbana es un segundo desafío que enfrenta la política de desarrollo alternativo. Para que ello se dé con éxito, es necesario mejorar la articulación interinstitucional de las entidades públicas y privadas que se encuentran dentro del territorio, es decir, configurar una nueva institucionalidad mixta en redes.

Estos plausibles objetivos, tienen que ser diseñados con estrategias diferenciadas para cada territorio, de acuerdo con sus particularidades agroecológicas, culturales, económicas y socio-políticas. Para lograrlo, es necesario que las comunidades y los poderes locales tengan una participación más activa en el diseño de los proyectos. Los avances en la descentralización del poder, no deben suspenderse, y por el contrario, es indispensable que sigan construyéndose en todos los niveles. Por lo tanto, se debe impulsar una política diseñada de abajo hacia arriba, con altos niveles de participación, concertación y con la asesoría de entidades y organizaciones especializadas.

La integración de municipios en mancomunidades y la participación más activa en el diseño, gestión y ejecución de las políticas públicas por parte de las Juntas de 
Acción Comunal, Cabildos y Consejos Comunitarios, son herramientas importantes de integración horizontal en el territorio.

Por su parte, el desarrollo alternativo debe integrarse de forma compleja a la política de desarrollo rural ejecutada por el Ministerio de Agricultura y a todos los estamentos de poder público a nivel nacional. En este sentido, reiteramos la necesidad de construir la institucionalidad necesaria, dentro de la cual sería propicio dar impulso a un Ministerio contra el Narcotráfico, con una dependencia importante de desarrollo alternativo que articule a todas las políticas públicas de desarrollo rural a nivel nacional.

En efecto, debe existir una total sincronía entre las directrices económicas, ambientales y políticas que propenden por la disminución de la pobreza rural, la desigualdad y la concentración de la propiedad rural. De igual forma, aspectos como el calentamiento global, el conflicto armado y el desplazamiento forzado, entre muchos otros, son aspectos fundamentales a la hora de abordar este complejo problema.

Sin importar la estrategia utilizada, como el subsidio condicionado de la experiencia Familias Guardabosques, o nuevos instrumentos de futuros gobiernos, el desarrollo alternativo debe considerar los conceptos discutidos anteriormente, para lograr erradicar los cultivos ilícitos de manera permanente y construir la paz con justicia social que necesita Colombia.

\section{BIBLIOGRAFÍA}

- Bosier, Sergio. 2003. Teorías y metáforas sobre desarrollo territorial. CEPAL. Santiago, Chile.

- Cortés, Mónica. 2007. Género y desarrollo alternativo en el contexto colombiano. En: Mujeres indígenas, territorialidad y biodiversidad en el contexto latinoamericano. Universidad Nacional de Colombia, Fundación Natura, Unión Mundial para la Naturaleza (UICN), Oficina de las Naciones Unidas contra la Droga y el Delito (UNODC). Bogotá, Colombia.

- De Janvry, Alain ; Sadoulet, Elizabeth. 2000. Cómo transformar en un buen negocio la inversión en el campesinado pobre: Nuevas perspectivas de desarrollo rural en América Latina. Banco Interamericano de Desarrollo. Washington D.C. USA. 2004. Hacia un enfoque territorial del desarrollo rural. En: Ponencia del Cuarto Foro Temático Regional de América Latina y el Caribe. San José, Costa Rica.

- Echeverri, Rafael. 2006. Enfoques del desarrollo territorial. En: Jornadas de reflexión y debate políticas agropecuarias, estrategias de desarrollo rural, seguridad alimentaria, pobreza rural, y servicios de extensión agrícola. IICA. San José, Costa Rica.

- García, Guillermo. 2000. Estrategia de Desarrollo Alternativo en Colombia. En: Cultivos llícitos en Colombia. Memorias del Foro realizado el 17 y 18 de Agosto de 2000 en la Universidad de los Andes. Bogotá, Colombia.

- Linck, Thierry. 2006. La economía y la política en la apropiación de los territorios. INRA. Francia.

- Mora, Jorge; Sumpsi, José. 2004. Desarrollo Rural: Nuevos enfoques y perspectivas . Cuadernos Fodepal. FAO. Santiago, Chile. 
- Ortiz, Cesar. 2000. La estrategia del Programa de Desarrollo Alternativo en Colombia. En: Cultivos llícitos en Colombia. Memorias del Foro realizado el 17 y 18 de Agosto de 2000 en la Universidad de los Andes. Bogotá, Colombia.

- Robledo, Jorge. 2007. El TLC recoloniza a Colombia. TR Ediciones. Manizales, Colombia.

- Schejtman, Alexander; Berdegué, Julio. 2003. Desarrollo Territorial Rural. RIMISP, BID. Santiago, Chile

- Sepúlveda, Sergio; Rodríguez Adrian; Echeverri, Rafael. Portilla, Melania. 2003. El enfoque territorial del desarrollo rural. IICA. San José, Costa Rica.

- SIMCI/UNODC. 2008. Censo de Cultivos de Coca. Monitoreo de Cultivos llícitos. Bogotá, Colombia.

- Sumpsi, José. 2006. Experiencias piloto de desarrollo local rural en América Latina: Lecciones del proyecto EXPIDER en Bolivia, Ecuador y Honduras. BID. Washington, D.C. USA.

- UNGASS, 1998. Resolución de la Asamblea General de las Naciones Unidas.

- UNODC. 2007. Informe Ejecutivo sobre el Seguimiento a los Programas Familias Guardabosques y Proyectos Productivos. Bogotá, Colombia.

\section{GLOSARIO}

PFGB: Programa Familias Guardabosques

DTR: Desarrollo Territorial Rural

UNGASS: Asamblea General de Naciones Unidas sobre el problema mundial de las drogas

SIMCI: Sistema Integrado de Monitoreo de Cultivos ilícitos

PLANTE: Plan Nacional de Desarrollo Alternativo

UNODC: Oficina de las Naciones Unidas contra la droga y el Delito

PPP: Programa Proyectos Productivos

IICA: Instituto Interamericano de Cooperación para la Agricultura

PSA: Pagos por servicios ambientales

CCVCS: Comités Comunitarios de Verificación y Control Social

JAC: Juntas de Acción Comunal

SENA: Centro Nacional de Aprendizaje

\section{NOTAS}

1. Antioquia: El Bagre, Zaragoza, Argelia; Bolívar: San Pablo, Cantagallo, Simití, Santa Rosa del Sur; Nariño: Albán, Buesaco, San Pablo, Colón, Belén y San 
Bernardo; Guaviare: San José del Guaviare, El Retorno; Magdalena: Santa Marta; Putumayo: Mocoa, Orito, La Hormiga, Villa Garzón; Tolima: Ataco, Natagaima; Boyacá: Otanche, Pauna; Cauca: La Sierra, San Sebastián, La Vega; Córdoba: Tierra Alta, Valencia; Huila: San Agustín, Pitalito, Saladoblanco, Oporapa, La Plata; Norte de Santander: Sardinata, Teorama; Chocó: Riosucio, Belén de Barirá, Carmen del Darién, Acandí; Meta: Puerto Rico, Vistahermosa; Santander: Bolívar, La Belleza, El Peñón, Sucre; Vaupés: Mitú 